\title{
The effect of flux on ion irradiation-induced precipitation in AISI-316L: an in-situ TEM
}

study

Ítalo M. Oyarzabal ${ }^{1,2 *}$, Matheus A. Tunes ${ }^{1}$, Osmane Camara $^{1}$, Emily Aradi ${ }^{1}$, Anamul H. Mir ${ }^{1}$, Graeme Greaves $^{1}$, Jonathan A. Hinks ${ }^{1}$, Paulo F. P. Fitchner ${ }^{2}$ and Stephen E. Donnelly ${ }^{1}$

University of Huddersfield, Queensgate, Huddersfield, United Kingdom

${ }^{2}$ Universidade Federal do Rio Grande do Sul (UFRGS), Porto Alegre, Brazil

*Corresponding author: italozabal@hotmail.com

Abstract

Thin foils of AISI 316L stainless steel were irradiated in-situ in a transmission electron microscope (TEM) with $325 \mathrm{keV} \mathrm{Xe}$ ions at $550^{\circ} \mathrm{C}$ at three different fluxes to study flux effects. The kinetics of the radiation-induced precipitation and the evolution of the precipitates were found to be correlated with the irradiation flux. At lower fluxes ( 1 and $2 \times 10^{12}$ ions $\left.\mathrm{cm}^{-2} \cdot \mathrm{s}^{-1}\right)$, cascade mixing played an important role in the accumulation of point defects within the austenite matrix, facilitating the formation of clusters which act as sinks for heterogeneous nucleation of precipitates with high areal density. At the highest flux $\left(4 \times 10^{12}\right.$ ions $\left.\cdot \mathrm{cm}^{-2} \cdot \mathrm{s}^{-1}\right)$ the cascade mixing favours the recombination of vacancies and interstitials which supresses the growth of existing precipitates beyond a certain total damage level. The results agree with a previous radiation-induced precipitation (RIP) model proposed by Wiedersich, Okamoto and Lam and further studied by Bruemmer, but a small modification is proposed when the flux is closer to the vacancy-interstitial recombination limit.

Keywords: Ion Irradiation; In-situ TEM; Austenitic Stainless Steel; Radiation-Induced Precipitation; Irradiation Flux.

\section{Introduction}

Structural components to be used in nuclear reactors must meet several engineering criteria depending on the specific range of conditions expected during the operational lifetime of the component. Since the beginning of the construction of Generation II Advanced Gas-Cooled Reactors (AGRs) in the 1960s, austenitic stainless steels (designated AISI-300) have been 
widely used as structural components for fuel cladding (the tubes which surround the fuel pellets) due to their high-temperature corrosion resistance and mechanical strength [1]. Austenitic stainless steels are also candidate materials for future Generation IV reactors such as super-critical water-cooled reactors (SCWRs) or lead-cooled reactors (LCRs) which will operate at higher temperatures and to higher irradiation fluences [1], [2]. The spatial variation of neutron flux within the core of a nuclear reactor presents a challenge for in-core material selections as this will result in different dose rates across the fuel assemblies. Therefore, the stability under different experimental conditions should also be considered when studying these materials.

Radiation damage affecting metal alloys, as well as other structural components of nuclear reactors, is a well-studied area [3],[4],[5],[6],[7],[8]. Radiation-induced segregation (RIS) and radiation-induced precipitation (RIP) present very important challenges when it comes to damage caused by irradiation which can significantly affect structural properties and long-term stability of the materials within nuclear reactors. The effects of experimental conditions and material variables due to RIS have been reviewed by Okamoto and Rehn in binary and ternary alloys [9] while a theory explaining RIS in concentrated alloys was proposed by Wiedersich et al. [10]. Jiao et al. [11] analysed the segregation and depletion of solute elements along grain boundaries in 304 stainless steel alloys and the way in which it affects RIP. Etienne et al. [12] observed $\mathrm{Ni}$ and $\mathrm{Si}$ enrichment and $\mathrm{Cr}$ depletion at grain boundaries in 316 stainless steel subjected to $10 \mathrm{MeV}$ Fe ion irradiation and showed that there is a greater annihilation of point defects at GBs in ultrafine-grained than in coarse-grained 316 austenitic steels [13]. The influence of RIS, RIP and irradiation-assisted stress-corrosion cracking (IASCC) on the stability and durability of austenitic steels as structural materials in Light Water Reactors (LWRs) has also been discussed extensively by Kenik and Busby [14].

A recent research study showed that for AISI 316L samples previously implanted with Ar and irradiated with $5 \mathrm{MeV}$ Au ions a change in the irradiation temperature can induce the formation and evolution of radiation-induced precipitates, which was not observed in the samples without the previous Ar implantation. It was shown that the formation of RIP is highly dependent on the previous concentration of vacancies [15]. Also, by changing the ion from $\mathrm{Au}$ to $\mathrm{Ag}$ and subjecting the AISI 316L samples to the same total amount of damage and temperature results in a change in the microstructure due to the larger production of vacancies in the denser collision cascades of $\mathrm{Au}$ [16].

In their work, Wiedersich, Okamoto and Lam (WOL) developed a model to analyse the influence of irradiation temperature and irradiation flux on RIS in austenitic stainless steels 
from the 300 series $[9,10,17]$. It was reported that RIS happens only within a certain range of combined temperature and flux. If the temperature is high enough and/or the flux is low enough, the increase in the thermal equilibrium concentration of vacancies prevents RIS; similarly, the recombination of vacancies with interstitials occurs at high fluxes and/or low temperatures [18]. These limits for RIS might affect the evolution of the microstructure of 300 series steels used as component materials for nuclear reactors and limit the use of different sources of irradiation to compare with the damage caused by neutrons.

The ion implantation technique is commonly used to induce radiation damage effects in materials for comparison with the damage generated due to neutron irradiation in a reactor [19], [20], [21], [22]. Displacements-per-atom (dpa) is a unit used to give an estimation of the damage induced in a material based on the average number of displacements suffered by the atoms from their lattice points. It can be calculated, in ion irradiation experiments, using The Stopping and Range of Ions in Matter (SRIM) Monte Carlo code [23]. For neutron irradiations dpa are generally calculated using the Norgett-Robinson-Torrens (NRT) model[24]. However, it is not clear that irradiation to an identical estimated dpa level with ions and neutrons will, in reality, yield the same damage level and/or morphology.[25]. Some adjustments to provide a more accurate comparison of totaldamage caused by different irradiation sources is a topic frequently discussed in the literature [26], [27]. For example, Mansur et al. showed that to better emulate neutron damage using ions a shift should be applied to the irradiation temperature as predicted via invariance theory [26]. Nordlund et al. [27] demonstrated that the NRT model overestimates the number of defects generated and underestimates the number of atom replacements in dpa calculations. Materials Test Reactors (MTRs) are commonly used to test structural materials under the experimental conditions inside power generation reactors. Nonetheless, using ion irradiation, it is possible to achieve high damage levels in a matter of hours (instead of years for a nuclear reactor) without activating the material under investigation [28].

In the current work, we report on the formation of precipitates in AISI-316L steel under in-situ $\mathrm{Xe}$ ion implantation for three different fluxes at $550^{\circ} \mathrm{C}$ within a transmission electron microscope (TEM) in the Microscope and Ion Accelerators for Materials Investigations (MIAMI-2) system at the University of Huddersfield [29]. Statistical analysis from bright-field TEM (BFTEM) images using Fresnel phase contrast and selected-area electron diffraction (SAED) were used to characterise the precipitates formed. It will be shown that the nucleation and growth of precipitates can vary significantly with irradiation flux and a deviation from the predicted limit in the WOL model discussed above will be proposed. 


\section{Materials and Methods}

Commercial AISI-316L stainless steel in the form of $200 \mu \mathrm{m}$ thick sheet was used as a starting material. To obtain electron transparent foils, $3 \mathrm{~mm}$ discs were cut from the sheets using a Gatan Model 3195 disc puncher and subsequently electropolished using a 10\% perchloric acid and 90\% methanol solution using a Tenupol-5 electrochemical jet polisher to obtain regions of about $100 \mathrm{~nm}$ thick. The samples were then subjected to an in-situ Xe ion irradiation with $325 \mathrm{keV}$ ions in the MIAMI-2 irradiation system at the University of Huddersfield in which microscopy and analysis are carried out using a Hitachi H-9500 TEM equipped with a $\mathrm{LaB}_{6}$ filament. In this system, the ion beam makes an angle of $18.7^{\circ}$ with the electron beam [29]. In addition to TEM imaging to show the formation of precipitates, SAED was also used to analyse the crystalline precipitates that formed in the matrix. The SRIM code was used in Kinchin-Pease (KP) mode to obtain the implantation and damage profiles as shown in fig. 1a and fig. 1b, respectively, for 316 stainless steel with a $100 \mathrm{~nm}$ thickness. The displacement energy, $E_{\mathrm{d}}$, was set to $40 \mathrm{eV}$ for the elements in the steel matrix [30]. The dpa profile (fig. 1b) reveals the varying damage levels as a function of target depth with peak dpa at a depth of about $30 \mathrm{~nm}$. The end fluence used in all experiments $\left(\Phi=8 \times 10^{15} \mathrm{at} . \mathrm{cm}^{-2}\right)$ was calculated to generate an average damage (for the $100 \mathrm{~nm}$ of thickness) of $20 \mathrm{dpa}$ and the flux, $\Phi$, was varied from $1 \times 10^{12}$ ions $\cdot \mathrm{cm}^{-2} \cdot \mathrm{s}^{-1}$ to $4 \times 10^{12}$ ions $\cdot \mathrm{cm}^{-2} \cdot \mathrm{s}^{-1}$ to achieve different average dpa rates (Table 2 ). All Xe irradiation experiments were performed at a temperature $T_{\mathrm{i}}=550{ }^{\circ} \mathrm{C}$ and at high vacuum $\left(P \approx 10^{-7}\right.$ mbar $)$.
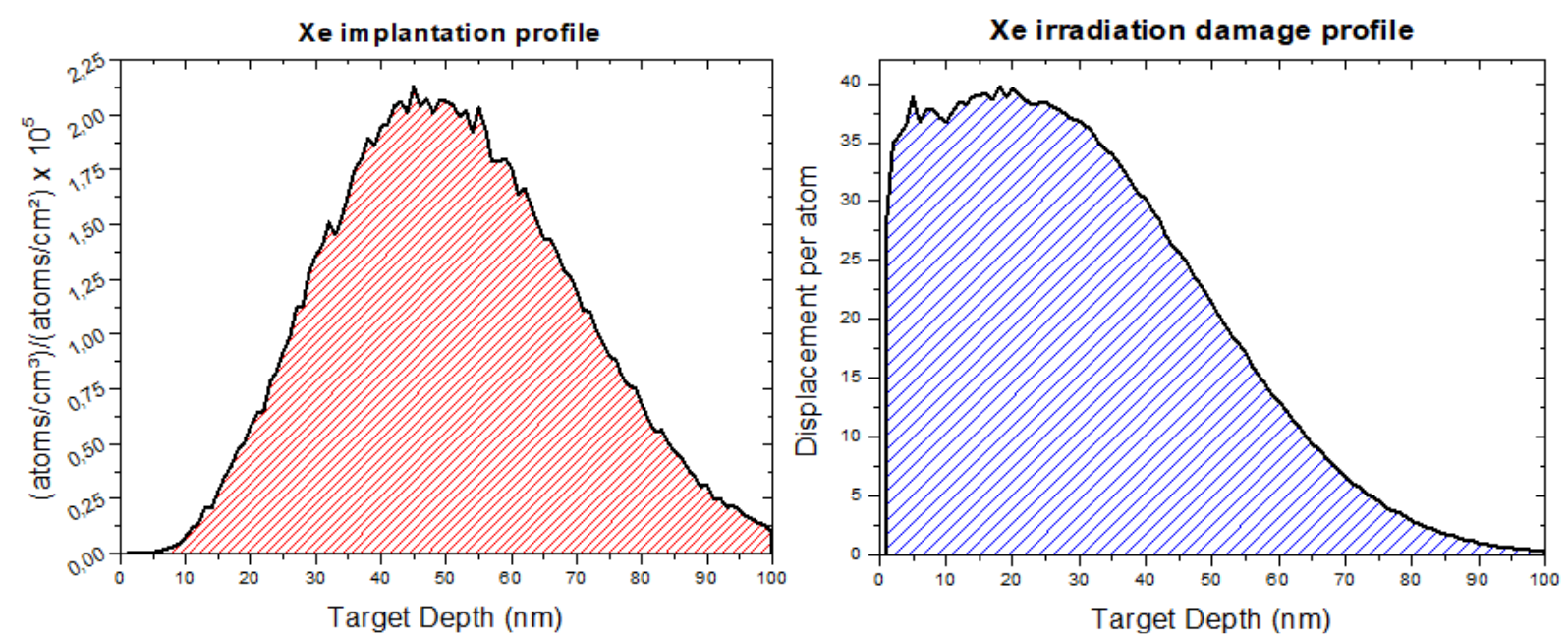

Figure 1: SRIM calculations in Kinchin-Pease(KP) modefor a $100 \mathrm{~nm}$ thick AISI 316 L stainless steel sample irradiated with $325 \mathrm{keV} \mathrm{Xe} \mathrm{ion} \mathrm{showing} \mathrm{(a)} \mathrm{the} \mathrm{implantation} \mathrm{profile} \mathrm{and}(b)$ the damage profile for a fluence of $\Phi=8 \times 10^{15}$ ions.cm- $\mathrm{cm}^{-2}$. 
Table 1: Nominal composition in weight percentage of AISI 316L austenitic steel.

\begin{tabular}{|c|c|c|c|c|c|c|c|c|c|}
\hline AISI & $\mathbf{C}$ & $\mathbf{M n}$ & $\mathbf{S i}$ & $\mathbf{P}$ & $\mathbf{S}$ & $\mathbf{C r}$ & Ni & Mo & Fe \\
[wt\%] & max. & max. & max. & max. & max. & & & & \\
\hline 316L & 0.03 & 2 & 0.75 & 0.045 & 0.03 & $16-18$ & $10-14$ & $2-3$ & Balance \\
\hline
\end{tabular}

Table 2: Flux and duration of Xe experiments.

\begin{tabular}{|c|c|}
\hline Flux $\left[\right.$ ions $\left.\cdot \mathbf{c m}^{-\mathbf{2}} \cdot \mathbf{s}^{-1}\right]$ & Experiment duration \\
\hline $\mathbf{1 \times 1 0 ^ { 1 2 }}$ & $\approx 2 \mathrm{~h}$ \\
\hline $\mathbf{2} \times \mathbf{1 0}^{\mathbf{1 2}}$ & $\approx 1 \mathrm{~h}$ \\
\hline $\mathbf{4} \times \mathbf{1 0}^{\mathbf{1 2}}$ & $\approx 30 \mathrm{~min}$ \\
\hline
\end{tabular}

\section{Results}

Figure 2 shows bright-field images in underfocus $(1000 \mathrm{~nm})$ condition (to obtain the best contrast for voids and bubbles, which appear as white dots surrounded by dark Fresnel fringes[31]) for three different samples (corresponding to the three different fluxes) over several steps during the irradiations. Figures $2 \mathrm{a}, 2 \mathrm{~b}$ and $2 \mathrm{c}$ correspond to the microstructural state of the steel matrix before the Xe irradiation $(0 \mathrm{dpa})$ showing the austenitic matrix at the irradiation temperature of $550^{\circ} \mathrm{C}$. The figures show regions containing grain boundaries and free of preexisting precipitates but exhibiting some faint contrast visible in the unirradiated samples under defocus condition that can be small cavities or surface roughness.

After an average damage of $5 \mathrm{dpa}$ (fluence of $2 \times 10^{15}$ ions $^{\cdot \mathrm{cm}^{-2}}$ ), for the flux of $1 \times 10^{12}$ ions $\mathrm{cm}^{-2} \cdot \mathrm{s}^{-1}$ in figure $2 \mathrm{~d}$ a system of small round crystalline precipitates with a mean diameter $\mathrm{d}_{\mathrm{m}}=10.8 \pm 2.0 \mathrm{~nm}$ is observed to form in the matrix. At the intermediate irradiation flux of $2 \times 10^{12}$ ions $\cdot \mathrm{cm}^{-2} \cdot \mathrm{s}^{-1}$ shown in figure $2 \mathrm{e}$, the system of precipitates presents a higher areal density with a mean diameter of $d_{\mathrm{m}}=20.5 \pm 2.6 \mathrm{~nm}$. In figure $2 \mathrm{f}$, the image shows an inhomogeneous system of precipitates and a bigger range of diameters with a mean diameter $\mathrm{d}_{\mathrm{m}}=31.9 \pm 7.1$ $\mathrm{nm}$ for the highest flux of $4 \times 10^{12}$ ions $\cdot \mathrm{cm}^{-2} \cdot \mathrm{s}^{-1}$.

Figures $2 \mathrm{~g}, 2 \mathrm{~h}$ and $2 \mathrm{i}$ show the images corresponding to irradiations after an average dose of $10 \mathrm{dpa}$ (fluence of $4 \times 10^{15}$ ions $\cdot \mathrm{cm}^{-2}$ ) and for all fluxes there was a small increase in the 
mean diameter of precipitates reaching $11.6 \pm 2.0,22.9 \pm 3.5$ and $33.3 \pm 9.2 \mathrm{~nm}$ for the low, intermediate and high fluxes, respectively.

Figures $2 \mathrm{j}, 2 \mathrm{k}$ and $2 \mathrm{l}$ show the images for the samples irradiated to $15 \mathrm{dpa}\left(6 \times 10^{15}\right.$ ions $\mathrm{cm}^{-2}$ ). For the smallest irradiation flux used, the system of precipitates showed a slight increase compared to the $10 \mathrm{dpa}$ case in the mean diameter, reaching a value of $\mathrm{d}_{\mathrm{m}}=14.1 \pm 2.3$ $\mathrm{nm}$. For the intermediate irradiation flux, there is the presence of bigger precipitates, indicating that at this point there is a higher agglomeration of the precipitates. For this case, there is a leap in the mean diameter value, reaching $\mathrm{d}_{\mathrm{m}}=35.64 \pm 6.02 \mathrm{~nm}$. For the highest flux case, the behaviour of the precipitate system remains stable, with a slight increase in the mean diameter, reaching $\mathrm{d}_{\mathrm{m}}=35.8 \pm 8.9 \mathrm{~nm}$.

The microstructures of the AISI 316L samples after irradiation (i.e. 20 dpa at a fluence of $8 \times 10^{15}$ ions $\mathrm{cm}^{-2}$ ) are shown in figures $2 \mathrm{~m}, 2 \mathrm{n}$ and $2 \mathrm{o}$. As in previous cases, the sample subjected to the lowest irradiation flux did not present significant changes with increasing irradiation fluence, leading to a final mean precipitate diameter of $\mathrm{d}_{\mathrm{m}}=15.9 \pm 2.9 \mathrm{~nm}$. For the intermediate flux, again there is a significant increase in the mean precipitate diameter indicating that for this combination of flux and temperature the increase in the total damage favours the cluster agglomeration and grow th of the precipitates. The final average diameter of precipitates in this case was $49.3 \pm 9.9 \mathrm{~nm}$. For the highest irradiation flux, a decrease is observed for the last $5 \mathrm{dpa}$ of irradiation indicating a stability of the precipitation system with fluence at this flux level with the final mean diameter being $32.8 \pm 9.1 \mathrm{~nm}$. Table 2 summarizes the distribution of mean diameters with flux for the different doses and Figure 3 shows the linear fittings for the three different irradiation fluxes with increasing fluence. 


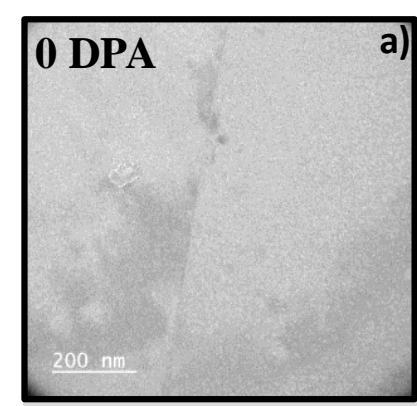

$\Phi=1 \times 10^{12}$ ions $\cdot \mathrm{cm}^{-2} \cdot \mathrm{s}^{-1}$
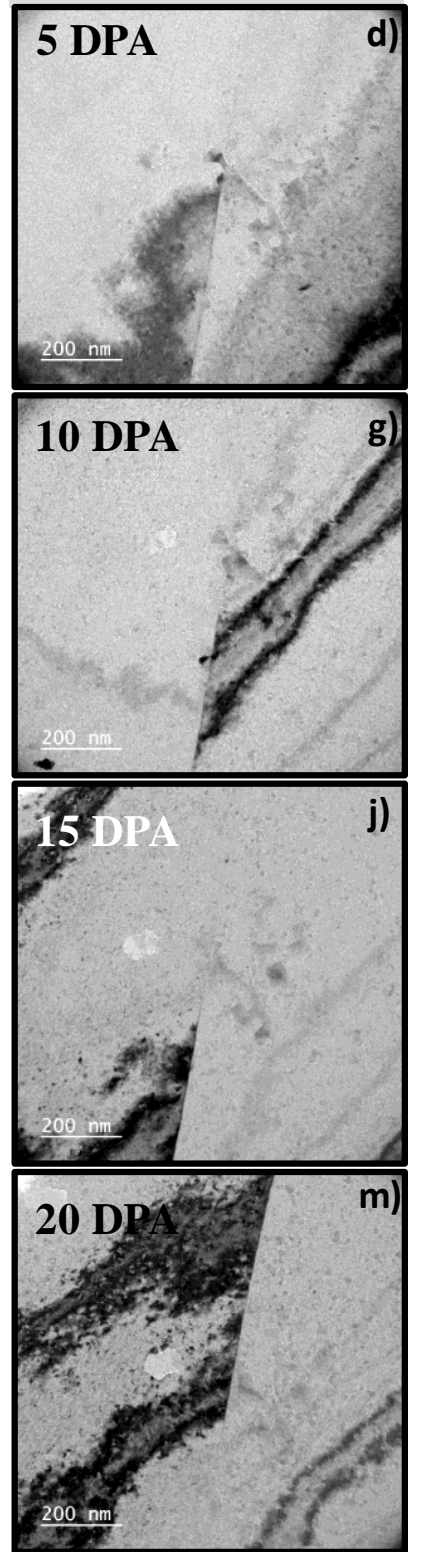

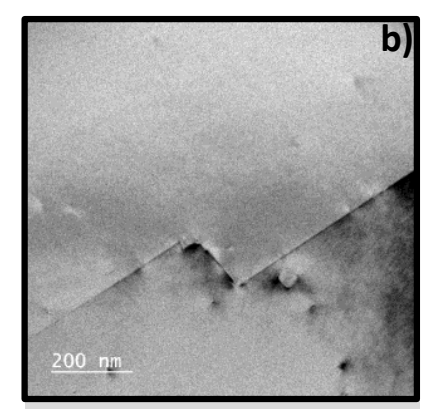

$\Phi=2 \times 10^{12}$ ions $\cdot \mathrm{cm}^{-2} \cdot \mathrm{s}^{-1}$
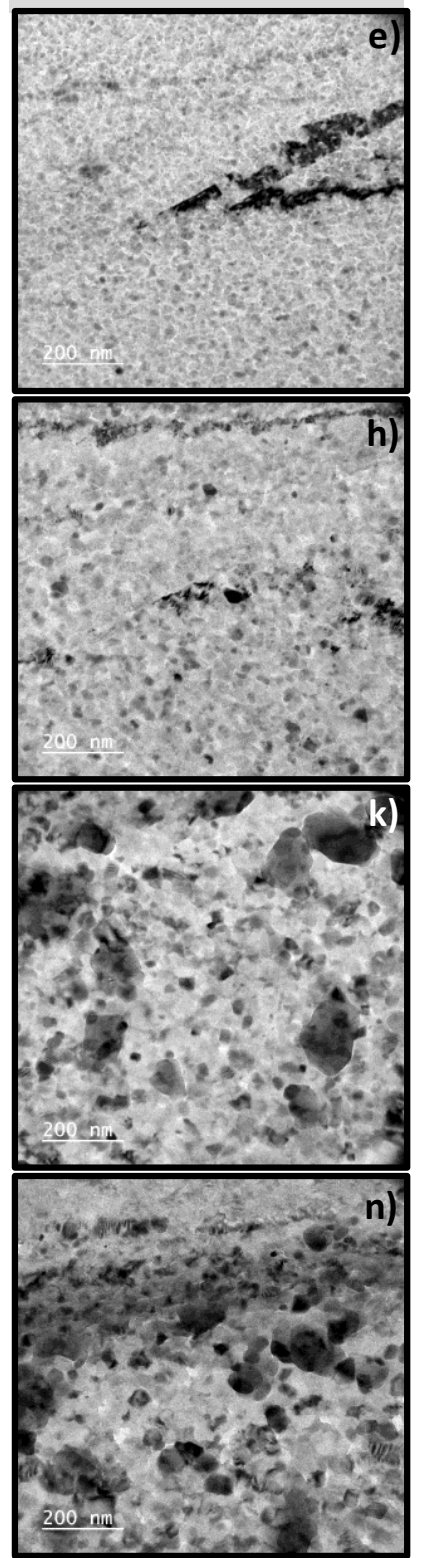

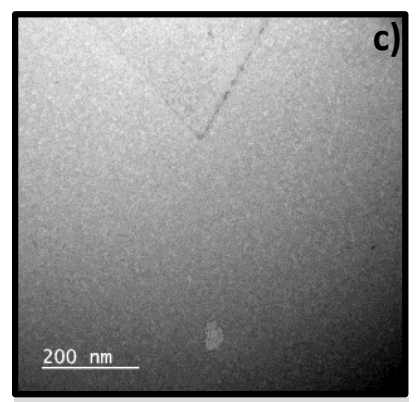

$\Phi=4 \times 10^{12}$ ions $\cdot \mathrm{cm}^{-2} \cdot \mathrm{s}^{-1}$
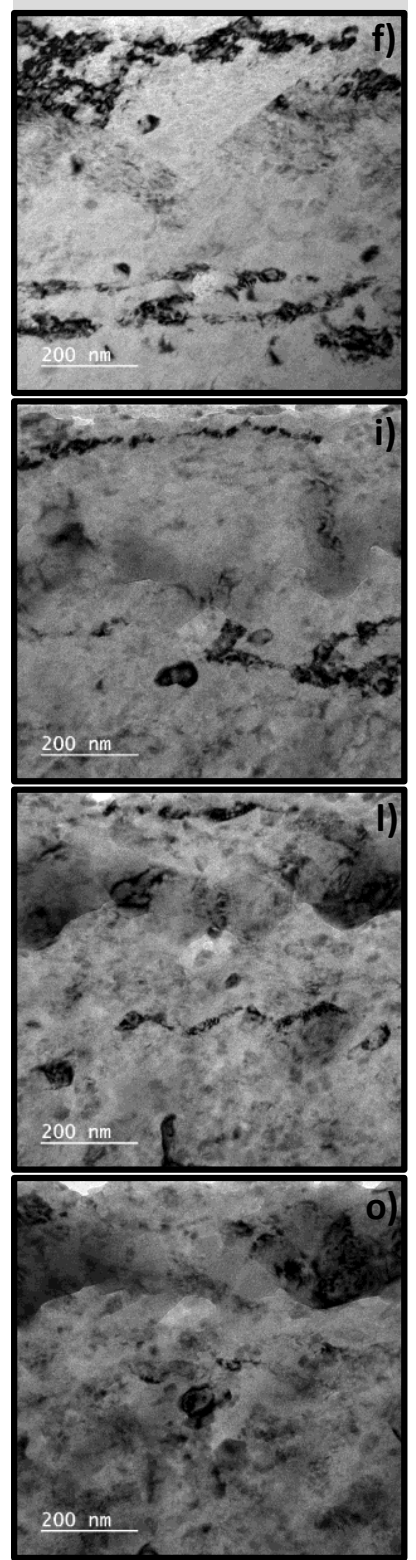

Figure 2: BFTEM micrographs for the three samples irradiated at the three different fluxes $\left(1 \times 10^{12}, 2 \times 10^{12}\right.$ and $4 \times 10^{12}$ ions $\left.\cdot \mathrm{cm}^{-2} \cdot \mathrm{s}^{-1}\right)$ at different fluence steps. Note: all the micrographs in the figure have the same scale. 
Table 3: Average precipitate sizes (diameter) for the irradiation conditions studied in this work.

\begin{tabular}{|c|c|c|c|c|}
\hline Fluxes[ions $\left.\cdot \mathrm{cm}^{-2} \cdot \mathrm{s}^{-1}\right]$ & 5 dpa & 10 dpa & 15 dpa & 20 dpa \\
\hline $1 \times 10^{12}$ & $10.8 \pm 2.0 \mathrm{~nm}$ & $11.6 \pm 2.0 \mathrm{~nm}$ & $14.1 \pm 2.4 \mathrm{~nm}$ & $15.9 \pm 2.9 \mathrm{~nm}$ \\
\hline $2 \times 10^{12}$ & $20.5 \pm 2.7 \mathrm{~nm}$ & $22.9 \pm 3.5 \mathrm{~nm}$ & $35.6 \pm 6.0 \mathrm{~nm}$ & $49.4 \pm 9.9 \mathrm{~nm}$ \\
\hline $4 \times 10^{12}$ & $31.9 \pm 7.1 \mathrm{~nm}$ & $33.3 \pm 9.3 \mathrm{~nm}$ & $35.8 \pm 8.9 \mathrm{~nm}$ & $32.8 \pm 9.1 \mathrm{~nm}$ \\
\hline
\end{tabular}

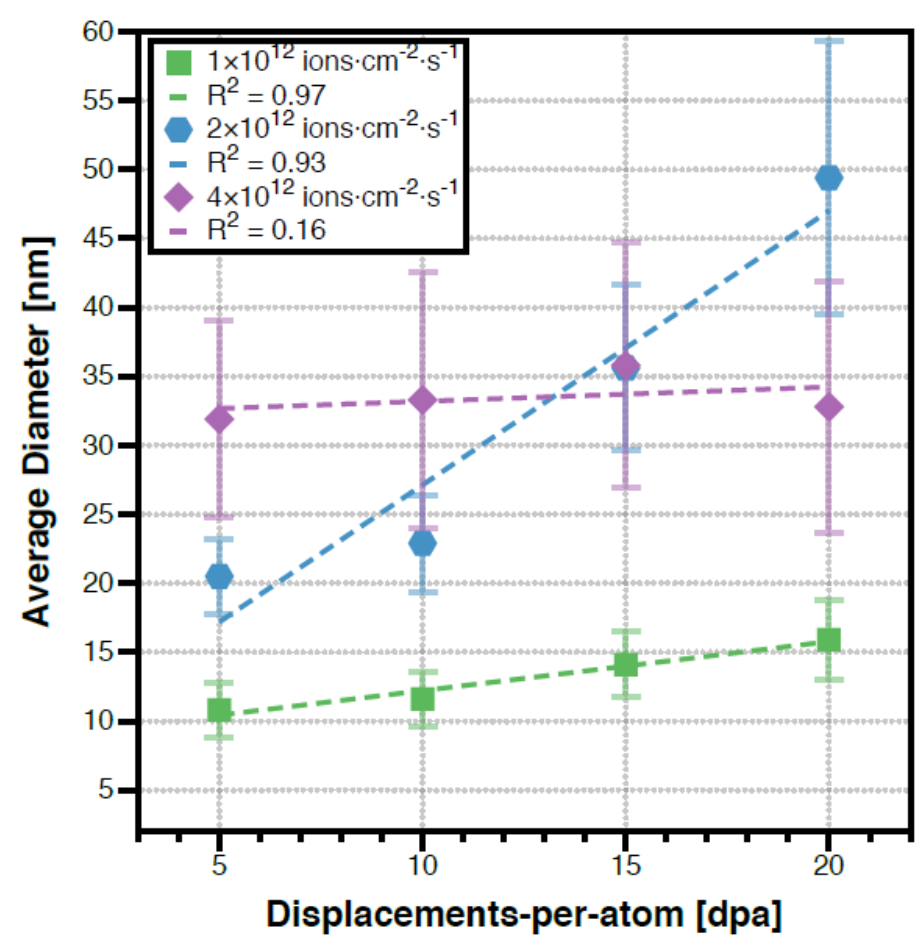

Figure 3: Average diameter of precipitates for the three different fluxes as a function of the average dpa value and their corresponding $R^{2}$ values.

Figure 4 shows the selected area electron diffraction (SAED) patterns for the three different fluxes before and after the irradiation to the total fluence. For all cases, at 0 dpa extra crystalline spots are observed in addition to the matrix ones indicating the presence of small crystalline clusters/precipitates before irradiation. With increasing damage level, the formation of crystalline Debye-Scherrer diffraction rings indicates the growth of pre-existing precipitates and the nucleation of new ones throughout the matrix. Comparing the 0 and $20 \mathrm{dpa}$ SAED patterns for the lowest irradiation flux, a slight increase in the number of spots and intensity of the rings was observed but not enough to detract from the matrix signal indicating that a significant part of the matrix did not transform into precipitates and the precipitates do not present a very high areal density. For $2 \times 10^{12}$ ions $\cdot \mathrm{cm}^{-2} \cdot \mathrm{s}^{-1}$, the $20 \mathrm{dpa}$ SAED pattern shows a high number of defined diffraction rings of enough intensity to supress the diffraction spots 
coming from the matrix. This indicates that the precipitates are present with a high number density and that a significant proportion of the matrix undergoes transformation into precipitates. In the highest flux case, it is observed that the rings are well defined but, in some orientations, along certain directions, they present a brighter intensity indicating that the precipitates have preferential orientations along which to grow or that the specimen has tilted into an orientation that favours these reflections.

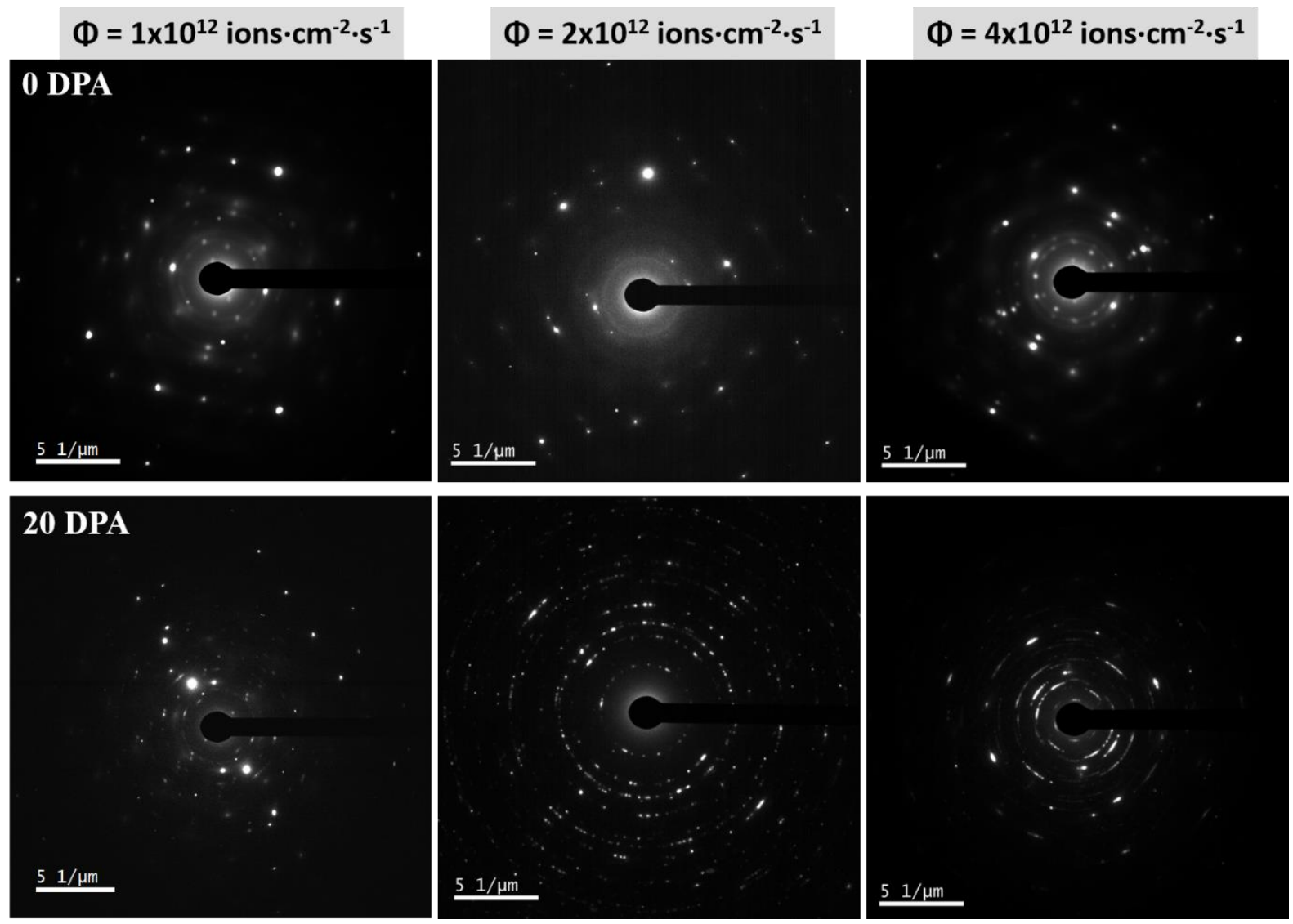

Figure 4: SAED patterns for the three distinct fluxes $\left(1 \times 10^{12}, 2 \times 10^{12}\right.$ and $4 \times 10^{12}$ ions $\left.\cdot \mathrm{cm}^{-2} \cdot \mathrm{s}^{-1}\right)$ at 0 and 20 dpa as average damage level.

\section{Discussion}

From the images presented in Figure 2, it can be observed that RIP takes place early in the process of Xe irradiation for all three fluxes. When a Xe ion impacts on the crystalline structure of AISI 316L, it can displace several atoms from their lattice positions which, depending on the kinetic energy transferred from the ion, can displace further atoms creating a collision cascade. Some defects will recombine and others will remain in the matrix as defects. Therefore, each ion creates a collision cascade that provides a density of defects that will diffuse and agglomerate forming defect clusters. These defect clusters act as nucleation centres for 
precipitates [32]. After nucleation, the growth of the precipitates is assisted by the diffusion of defects at the irradiation temperature of $550{ }^{\circ} \mathrm{C}$.

The three different fluxes present different time intervals for a following incoming ion to impact on an area that has been previously impacted sample which may affect the stability of defect clusters and affect their ability to grow. Using the SRIM code in full cascade mode, it is possible to estimate the radius of a collision cascade for a $325 \mathrm{keV} \mathrm{Xe} \mathrm{ion} \mathrm{as} \mathrm{approximately} 15$ $\mathrm{nm}$. Using this value, combined with the flux it is possible to determine the average time interval for a following ion to impact upon the same area and interact with the cascade created by the previous ion, leading to cascade mixing. This cascade mixing is estimated based only on the projected volume of the cascade collision for one Xe ion, not considering the expansion of the interaction volume with time which may be caused by the migration of defects. Figure 5 shows the time interval for the following ion to hit the area created by a collision cascade of radius R.

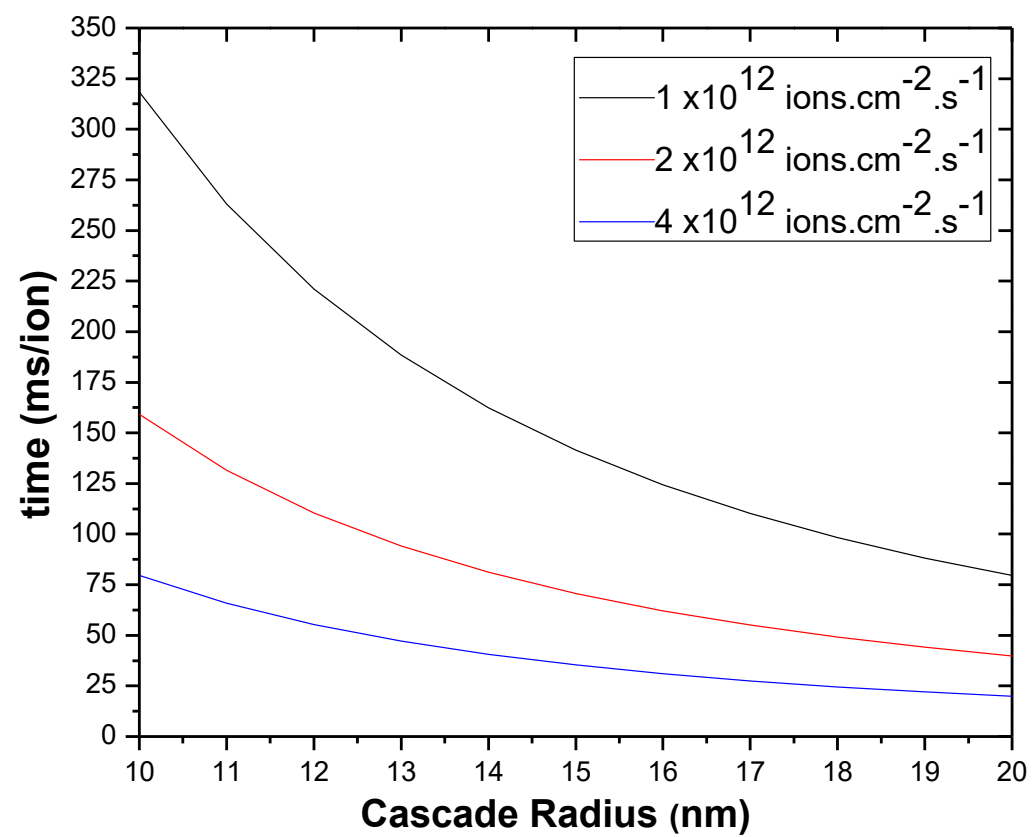

Figure 5: Time interval between two consecutive ions hitting the same area in function of the collision cascade radius.

For the predicted approximate radius of the collision cascade for a Xe ion of $15 \mathrm{~nm}$, the time interval between two consecutive ions is $\approx 35,70$ and $140 \mathrm{~ms}$ for the fluxes of 4,2 and $1 \times 10^{12}$ ions $\cdot \mathrm{cm}^{-2} \cdot \mathrm{s}^{-1}$, respectively. According to Was [33], the annealing and defect migration after a cascade collision lasts up (in general) to the second scale (Figure 6). This implies that when the next ion comes, defects created in a previous cascade are still migrating and can suffer interference from the incoming ion. 


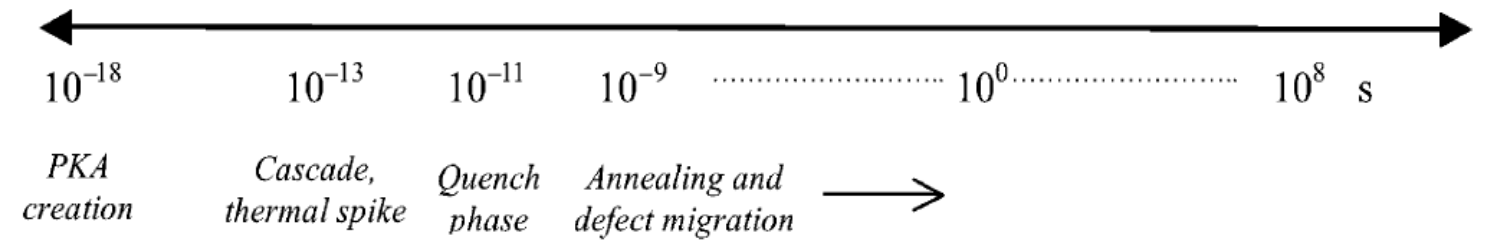

Figure 6: Timescale of events after the collision of an ion with a material[33].

For the irradiation flux of $1 \times 10^{12}$ ions $\cdot \mathrm{cm}^{-2} \cdot \mathrm{s}^{-1}$, the precipitates present a growth in the mean diameter with increasing fluence, starting at $10.8 \pm 2.0 \mathrm{~nm}$ at $5 \mathrm{dpa}$ and reaching $15.9 \pm 2.9 \mathrm{~nm}$ at $20 \mathrm{dpa}$. Considering the constant temperature of $550^{\circ} \mathrm{C}$ maintained during each experiment, for the irradiation flux of $1 \times 10^{12}$ ions $\cdot \mathrm{cm}^{-2} \cdot \mathrm{s}^{-1}$ we assume that there is no significant cascade mixing, considering that the time interval between two consecutives ion to hit the same area is $\approx 140 \mathrm{~ms}$, meaning that when each ion reaches the sample there are no significant mixing with defects from previous cascades that affects the process of nucleation and growth of precipitates.

For the intermediate irradiation flux, at $5 \mathrm{~d}$ pa the average diameter of $20.5 \pm 2.7 \mathrm{~nm}$ was almost twice that for the smallest flux. This is an indication that, for this flux, cascade mixing from consecutive ions is now occurring. In other words, it becomes likely that any given ion can hit the sample and generate a cascade in a volume in which the recombination and/or diffusion of point defects due to an earlier ion has not yet completed; this then means that the defect concentration is still significantly elevated above equilibrium enabling increased agglomeration of interstitials and consequently the nucleation and growth of precipitates. For $10 \mathrm{dpa}$, there was a slight increase in the mean diameter to a value of $22.9 \pm 3.5 \mathrm{~nm}$. Although, at $15 \mathrm{dpa}$, the increase in the mean diameter value was higher, reaching $35.6 \pm 6.0 \mathrm{~nm}$. This phenomenon might be explained by an absence of nucleation of new precipitates, considering the hypothesis that the free energy for precipitates to grow is smaller in this case than the nucleation energy. In this case, it is favourable for the existing precipitates to grow, resulting in an increase in the mean diameter. A similar result was observed for the last $5 \mathrm{dpa}$ of irradiation to $20 \mathrm{dpa}$, in which the final mean diameter reached a value of $49.3 \pm 9.9 \mathrm{~nm}$.

After $5 \mathrm{~d}$ pa of damage for the highest irradiation flux, a mean diameter of $31.9 \pm 7.1 \mathrm{~nm}$ was measured which was bigger than both previous cases for smaller fluxes. Again, it is expected that this is due to an increase in the cascade mixing as described above. A slight increase occurred up to doses of 15 dpa to $35.8 \pm 8.9 \mathrm{~nm}$. After this point, the mean diameter showed a small decrease to reach a final value of $32.8 \pm 9.1 \mathrm{~nm}$ at $20 \mathrm{dpa}$. This reduced growth rate can be explained by the dissolution of growing clusters, which is more evidently observed only for the second half of the experiment. The increased irradiation flux and consequent increase in the cascade mixing will likely lead to an increase in the ballistic collisions suffered 
by the migrating clusters which prevented their agglomeration, mitigating the growth and the formation and growth of precipitates. We can also observe, considering the effects created by different fluxes, that the time interval between two consecutive ions is very important to determine whether the precipitation growth will be enhanced or supressed by irradiation - only a few tens of milliseconds appears to be sufficient to change the dominant effect.

Linear fittings presented in figure 3 (along with $R^{2}$ coefficient of determination) show that, for the fluxes of $1 \times 10^{12}$ and $2 \times 10^{12}$ ions $\cdot \mathrm{cm}^{-2} \cdot \mathrm{s}^{-1}$, the mean diameter follows a rather linear grow th throughout the irradiation process. For the $4 \times 10^{12}$ ions $\cdot \mathrm{cm}^{-2} \cdot \mathrm{s}^{-1}$ flux, the $R^{2}$ indicates that the average diameter does not follow a linear behaviour with increasing fluence. According to Bruemmer et al. [18], this can be explained because for the same irradiation temperature, there is a certain level of irradiation flux where RIS is supressed due to the recombination of vacancies with interstitials. For this case, a high concentration of defects is produced and the thermal diffusion, as well the thermal equilibrium concentration of vacancies, are kept constant so these defects do not migrate long distances when a new ion hits the sample, and they mostly suffer collision with the cascade generated by the incoming ion, leading to recombination, supressing the agglomeration and, consequently, the formation of precipitates. This model proposes an interval where only radiation-induced-segregation (RIS) occurs, delimited by a combination of temperature and irradiation flux.

The results obtained in this work lies close to the lower limit of the curve proposed by Wiedersich, Okamoto and Lam, where the recombination of vacancies and interstitials starts to mitigate RIS, as discussed above [10,34]. Furthermore, the evidence shown in this present work suggests a non-linear relationship between the irradiation flux and the temperature in the WOL's model close to its lower limit (i.e. when the flux is high enough to induce RIS but not high enough so recombination of vacancies with interstitials suppress RIS), where the fluence plays an important role to drive the austenite phase towards a more stable thermodynamic equilibrium. This represents a deviation of the original straight line predicted by the model.

Considering the chemical composition of the alloy used in this work and the occurrence of RIP as well as its accelerated kinetics by RIS reported in the literature under similar irradiation conditions[35], we assume that the precipitates observed in this work are probably carbide phases, most likely the $\mathrm{M}_{23} \mathrm{C}_{6}$, since this phase presents higher stability (compared to other carbide phases, as $\mathrm{M}_{6} \mathrm{C}$ and $\mathrm{MC}$ ) under thermodynamic equilibrium within the austenitic matrix at this temperature[36]. Electron diffraction Debye-Scherrer rings did not provide a full capability to identify the precipitates, due to imprecisions and lack of resolution in the measurement of rings leading to an inability to discriminate between two different carbide 
phases, as they have very similar lattice parameters. Furthermore, chemical characterization via STEM-EELS (Electron Energy Loss Spectroscopy) would be required to better identify the precipitates in future work, as the probe size provides a better resolution for the measurement and the Electron Energy Loss Spectroscopy has a higher resolution for low $-\mathrm{Z}$ elements, like carbon.

\section{Conclusions}

The microstructural evolution of the AISI $316 \mathrm{~L}$ steel matrix under $\mathrm{Xe}$ ion implantation/irradiation at three different irradiation fluxes (thus three different average damage rates), at the same irradiation temperature of $550{ }^{\circ} \mathrm{C}$ and to the same total fluence was studied with a focus on the formation and nucleation of radiation-induced precipitates (metallic carbides).

For the two lower fluxes $\left(1 \times 10^{12}\right.$ and $2 \times 10^{12}$ ions $\left.\cdot \mathrm{cm}^{-2} \cdot \mathrm{s}^{-1}\right)$ a linear relationship between the size and areal density of the precipitates with increasing damage was observed. Such experimental observations are in good agreement with the RIP model proposed by Wiedersich, Okamoto and Lam. However, at the higher flux $\left(4 \times 10^{12}\right.$ ions $\left.\cdot \mathrm{cm}^{-2} \cdot \mathrm{s}^{-1}\right)$ a reduction in the size of the precipitates for the interval 15-20 dpa was observed. Therefore, it is proposed that the possible cascade mixing due to an increase in the flux may significantly affects both kinetics of diffusion and agglomeration of defects. An increase in the cascade mixing may lead to faster clustering of displaced lattice defects, thus resulting in an increase of precipitates sizes and their areal density, as observed in the experiments with fluxes of $1 \times 10^{12}$ and $2 \times 10^{12}$ ions $\cdot \mathrm{cm}^{-2} \cdot \mathrm{s}^{-1}$. At the same time, the cascade mixing can also contribute to the dissolution of clusters and precipitates which could explain such a trend in size reduction at higher doses. Therefore, the major conclusion of this present investigation is that the phenomenon of RIP in austenitic stainless steels is not necessarily linear with the irradiation flux for a fixed irradiation temperature.

In this way, the slight non-linear deviation in precipitate sizes as a function of dose that was observed at higher fluxes may be an indication that earlier RIP models need to be modified to include such considerations of cascade mixing when the irradiation conditions are closer to the recombination limit.

This work also indicates an interesting limitation on the use of ion irradiation to emulate the behaviour of nuclear reactors, because due to the lower interaction of neutrons, it is not possible to achieve such effects of cascade mixing, especially at a level high enough to supress 
the precipitation growth. This implies that we need to be careful when using one of the most advantageous effects of ions to emulate neutrons: the defect formation rate. Whilst it is possible to achieve with ions the amount of damage in a matter of hours that would take years in a nuclear reactor environment, increasing the ion irradiation flux to accelerate the damage may lead to undesirable effects and mislead interpretations.

Further experimental studies at atomic level or using molecular dynamics simulations are needed to assess the stability of defect clusters (and prior growth of extended precipitates) under irradiation.

\section{Acknowledgements}

IMO would like to acknowledge the brazilian research agency "Coordenação de Aperfeiçoamento de Pessoal de Nível Superior (CAPES)" for funding his internship at the MIAMI facilities in the University of Huddersfield, United Kingdom. All the authors are grateful to the Engineering and Physical Sciences Research Council of the United Kingdom for funding the MIAMI-2 under grant number EP/M028283/1 and also for funding the UKNational Ion Beam Centre (UKNIBC) of which MIAMI is a part.

\section{References}

[1] C.R.F. Azevedo, Selection of fuel cladding material for nuclear fission reactors, Eng. Fail. Anal. 18 (2011) 1943-1962. https://doi.org/10.1016/j.engfailanal.2011.06.010.

[2] K.L. Murty, I. Charit, Structural materials for Gen-IV nuclear reactors : Challenges and opportunities, J. Nucl. Mater. $383 \quad$ (2008) 189-195. https://doi.org/10.1016/j.jnucmat.2008.08.044.

[3] J.T. Maziasz, P. J., Busby, Properties of Austenitic Steels for Nuclear Reactor Applications, in: R.J.M. Konings (Ed.), Compr. Nucl. Mater. - Vol. 2, Elsevier B.V., 2012: p. 658. https://doi.org/10.1016/B978-0-12-088576-3.50063-0.

[4] K.L. Murty, I. Charit, An Introduction to Nuclear Materials: Fundamentals and Applications, 1st ed., Wiley-VCH, 2013.

[5] F.A. Garner, Radiation Damage in Austenitic Steels, 2012. https://d oi.org/10.1016/B978-0-08-056033-5.00065-3.

[6] M.A. Tunes, C.G. Schön, G. Greaves, Radiation-induced precipitation with concurrent bubbles formation in an austenitic stainless steel (AISI-348), Materialia. (2019) 100408. 
https://doi.org/10.1016/j.mtla.2019.100408.

[7] R.J.M. Konings, Comprehensive Nuclear Materials: Basic Aspects of Radiation Effects in Solids, 2012.

[8] R.J.M. Konings, Comprehensive Nuclear Materials: Radiation Effects in Structural and Functional Materials for Nuclear Applications, 2012.

[9] P.R. Okamoto, L.E. Rehn, Radiation-induced segregation in binary and ternary alloys, J. Nucl. Mater. 83 (1979) 2-23.

[10] H. Wiedersich, P.R. Okamoto, N.Q. Lam, A Theory of Radiation-Induced Segregation in Concentrated Alloys, J. Nucl. Mater. 83 (1979) 98-108.

[11] Z. Jiao, G.S. Was, Novel features of radiation-ind uced segregation and radiation-induced precipitation in austenitic stainless steels, Acta Mater. 59 (2011) 1220-1238. https://doi.org/10.1016/j.actamat.2010.10.055.

[12] A. Etienne, B. Radiguet, N.J. Cunningham, G.R. Odette, P. Pareige, Atomic scale investigation of radiation-induced segregation in austenitic stainless steels, J. Nucl. Mater. 406 (2010) 244-250. https://doi.org/10.1016/j.jnucmat.2010.08.043.

[13] A. Etienne, B. Radiguet, N.J. Cunningham, G.R. Odette, R. Valiev, P. Pareige, Comparison of radiation-induced segregation in ultrafine-grained and conventional 316 austenitic stainless steels, Ultramicroscopy. $111 \quad$ (2011) 659-663. https://doi.org/10.1016/j.ultramic.2010.12.026.

[14] E.A. Kenik, J.T. Busby, Radiation-induced degradation of stainless steel light water reactor internals, Mater. Sci. Eng. R Reports. 73 (2012) 67-83. https://doi.org/10.1016/j.mser.2012.05.002.

[15] I.M. Oyarzabal, M.D.M. Timm, W.M. Pasini, F.S.M. De Oliveira, F. Tatsch, L. Amaral, P.F.P. Fichtner, Influence of Ar Implantation on the Precipitation in Au Ion Irradiated AISI 316L Solution Annealed Alloy, in: MRS Adv., 2018. https://d oi.org/10.1557/adv.2018.414.

[16] M.M. Timm, Í.M. Oyarzabal, F. Tatsch, L. Amaral, P.F.P. Fichtner, Au and Ag ion irradiation effects on the carbide precipitation and Ar bubble formation in solubilized AISI 316L alloys, in: Nucl. Inst. Methods Phys. Res. B, Elsevier, 2018: pp. 1-5. https://doi.org/10.1016/j.nimb.2018.12.031.

[17] S.M. Bruemmer, L.A. Charlot, J.S. Vetrano, E.P. Simonen, Radiation-induced grain boundary segregation in austenitic stainless steels, in: Mater. Res. Soc. Symp. - Proc., 1995.

[18] M.S. Bruemmer, L.A. Charlot, J.S. Vetrano, E.P. Simonen, Radiation-Induced Grain 
Boundary Segregation in Austenitic Stainless Steels, in: MRS Proc., 1994: pp. 119-129.

[19] G.S. Was, Z. Jiao, E. Getto, K. Sun, A.M. Monterrosa, S.A. Maloy, O. Anderoglu, B.H. Sencer, M. Hackett, Emulation of reactor irradiation damage using ion beams, Scr. Mater. 88 (2014) 33-36. https://doi.org/10.1016/j.scriptamat.2014.06.003.

[20] O. V Ogorodnikova, V. Gann, Simulation of neutron-induced damage in tungsten by irradiation with energetic self-ions, J. Nucl. Mater. 460 (2015) 60-71.

[21] R.S. Nelson, D.J. Mazey, J.A. Hudson, The use of ion accelerators to simulate fast neutron-induced voidage in metals, J. Nucl. Mater. 37 (1970) 1-12. https://d oi.org/10.1016/0022-3115(70)90176-5.

[22] N.H. Packan, K. Farrell, J.O. Stiegler, Correlation of neutron and heavy-ion damage, J. Nucl. Mater. 78 (1978) 143-155. https://doi.org/10.1016/0022-3115(78)90513-5.

[23] www.srim.org, (n.d.).

[24] M.J. Norgett, M.T. Robinson, I.M. Torrens, A proposed method of calculating displacement dose rates, Nucl. Eng. Des. 33 (1975) 50-54. https://doi.org/10.1016/00295493(75)90035-7.

[25] G.S. Was, Challenges to the use of ion irradiation for emulating reactor irradiation, (2017). https://d oi.org/10.1557/jmr.2015.73.

[26] L.K. Mansur, Correlation of neutron and heavy-ion damage. II. The predicted temperature shift if swelling with changes in radiation dose rate, J. Nucl. Mater. 78 (1978) 156-160. https://doi.org/10.1016/0022-3115(78)90514-7.

[27] K. Nordlund, S.J. Zinkle, A.E. Sand, F. Granberg, R.S. Averback, R. Stoller, T. Suzudo, L. Malerba, F. Banhart, W.J. Weber, F. Willaime, S.L. Dudarev, D. Simeone, Improving atomic displacement and replacement calculations with physically realistic damage models, Nat. Commun. (2018) 1-8. https://doi.org/10.1038/s41467-018-03415-5.

[28] Standard Practice for Neutron Radiation Damage Simulation by Charged-Particle, 96 (2015) 1-20.

[29] G. Greaves, A.H. Mir, R.W. Harrison, M.A. Tunes, S.E. Donnelly, J.A. Hinks, New Microscope and Ion Accelerators for Materials Investigations ( MIAMI-2 ) system at the University of Huddersfield, Nucl. Inst. Methods Phys. Res. A. 931 (2019) 37-43.

[30] R.E. Stoller, M.B. Toloczko, G.S. Was, A.G. Certain, S. Dwaraknath, F.A. Garner, On the use of SRIM for computing radiation damage exposure, Nucl. Instruments Methods Phys. Res. B. 310 (2013) 75-80.

[31] M.L. Jenkins, Characterization of Voids and Bubbles, in: Charact. Radiat. Damage by Transm. Electron Microsc., 2001: p. 16. https://www.crcpress.com/Characterisation-of- 
Radiation-Damage-by-Transmission-Electron-Microscopy/Jenkin s-

Kirk/p/book/9780750307482\#googlePreviewContainer.

[32] D.A. Porter, K.E. Easterling, Diffusion, in: Phase Transform. Met. Alloy., 1992: pp. 60110.

[33] G. Was, The Damage Cascade, in: Fundam. Radiat. Mater. Sci., 2007: pp. 125-155.

[34] P.R. Okamoto, H. Wiedersich, Segregation of alloying elements to free surfaces during irradiation, J. Nucl. Mater. 53 (1974) 336-345.

[35] G. Was, Phase Stability under Irradiation, in: Fundam. Radiat. Mater. Sci., 2007: pp. 433-491.

[36] P.J. Maziasz, C.J. McHargue, Microstructural evolution in annealed austenitic steels during neutron irradiation, Int. Mater. Rev. 32 (1987) 190-219. 